\title{
Role of Probiotics on Oral Health - A Randomized, Double Blind, Placebo-Controlled Microbiological Study
}

\author{
Shivani Dhawan ${ }^{1}$ and Rajan Dhawan ${ }^{2}$ \\ ${ }^{1}$ Department of Perioidontology, National Dental College and Hospital, \\ Derrabassi (Mohali), Punjab, India \\ ${ }^{2}$ Department of Conservative Dentistry, National Dental College and Hospital, \\ Derrabassi (Mohali), Punjab, India
}

Correspondence should be addressed to: Shivani Dhawan; endorajan@gmail.com

Received 20 May 2013; Accepted 27 June 2013; Published 27 August 2013

Academic Editor: Seicho Makihira

Copyright (C) 2013 Shivani Dhawan and Rajan Dhawan. Distributed under Creative Commons CC-BY 3.0

\begin{abstract}
The aim of this study was to investigate commercially available combined probiotic formulation for its effect on plaque, gingivitis and salivary Streptococcus mutans levels in subjects with chronic gingivitis. A total of 36 subjects were finally enrolled in a double blind placebo controlled randomized trial. Selected subjects were randomly divided in two groups; Group A (Control group) with 17 subjects, receiving placebo tablets twice daily and Group B (Probiotic group) with 19 subjects receiving probiotic tablets twice daily. The study consisted of two 2 weeks periods, a two week intervention period (T1-T2) and a two week post treatment period (T2-T3). Clinical parameters and bacterial counts of salivary Streptococcus mutans, were evaluated at the baseline (T1), at the completion (T2) of medication and 2 weeks after medication (T3). On comparative evaluation between the two groups, results indicated that Group-B (Probiotic group) exhibited statistically significant reduction in Plaque Index, Gingival index and Streptococcus mutans level than Group-A (Control group) over the entire span of the study. Our results indicated that probiotic could be useful in the improvement/ maintainance of oral health.
\end{abstract}

Keywords: Probiotic, Streptococcus mutans, caries, gingivitis.

\section{Introduction}

Dental plaque, a biofilm of microorganisms on the tooth surface, is an important etiological factor in the development of most common oral diseases - dental caries, gingivitis and destructive periodontal diseases. ${ }^{22}$ In dental practice, the control of oral inflammation typically involves the use of mechanical or chemical means to remove biofilm. Despite the best efforts by dental professionals to sterilize the oral cavity, the oral cavity willinevitably repopulate with oral bacteria. In unfavourable oral envoirnment the disease persists and more therapeutic measures will be required in future. Little attention has been paid to the identification of health associated and potentially beneficial bacterial species that may reside in the oral cavity. 
Bacteriotherapy in the form of probiotics seems to be a natural way to maintain health and protect oral tissues from disease. This article endeavors to introduce the concept of probiotics in the oral cavity.

The basic principle of probiotics is to use good bacteria to compete against pathogenic bacteria. The term probiotic, which literally means "for life" was first coined in the 1960's by Lilly and Stillwell. ${ }^{22}$ According to the World Health Organization, probiotic bacteria are defined as live micro-organisms which, when administered in adequate amounts, confer a health benefit on the host. ${ }^{6}$ The interest in such an alternating way to cobat infections is rapidly growing especially in the light of the frequent use of antibiotics with a subsequent risk for development of resistant strains.

Bacterial endotoxins and antigens, together with some metabolic by-products produced by the pathogens in the dental biofilm, invariably lead to gingivitis and subsequently periodontitis.

Streptococcus mutans has been implicated as one of the major and most virulent of the caries producing microorganisms. ${ }^{\mathbf{1}, 12}$ It can colonize the tooth surface and initiate biofilm formation by their ability to synthesize extracellular polysaccharides from sucrose, mainly water-insoluble glucan, using the enzyme glucosyltransferase. ${ }^{24}$ Inhibiting the colonization of Streptococcus mutans on the tooth surface is believed to prevent the formation of biofilm and development of dental caries.

In the oral cavity, probiotics adhere to dental tissues as a part of biofilm, acting as a protective lining. Such a biofilm keeps bacterial pathogens off oral tissues by filling a space which could have served as niche for pathogens in future; and competing with cariogenic bacteria and periodontal pathogens growth. ${ }^{4}$

To be able to exert probiotic properties in the oral cavity, however, it is essential for the microorganism to resist the oral envoirnmental conditions, to be able to adhere to saliva coated surfaces, to colonize and grow in the mouth, and to inhibit oral pathogens. The putative probiotic species also needs to be safe for the host. Kligler and Cohrssen (2008) summarize that significant adverse effects after the use of probiotic are rare..$^{\mathbf{1 0}}$

The most commonly used and studied probiotic are lactic acid bacteria, in particular Lactobacillus spp., and Bifidobacterium spp. ${ }^{\mathbf{2 6}}$

To determine the effects of probiotic on oral health promotion, we conducted a double blind, placebo-controlled randomized clinical trial in healthy subjects with gingivitis. The specific aim of this study was to investigate the effect of combined probiotic formulation on plaque, gingivitis and caries during and after discontinuation of administration.

\section{Objectives}

To clinically evaluate the effect of probiotic on

- Plaque accumulation

- Gingival inflammation

- Caries by estimating the level of Streptococcus mutans in saliva.

\section{Materials and Methods}

\section{Probiotic Product}

The study product (capsule BifilacHp) contained Lactobacillus sporogens 100 million, Streptococcus faecalis T-110JPC 60 million, Clostridium butyrium TO-A 4 million, Bacillus mesentricus TO-A JPC 2 million. Combination of probiotic strains has been used that may act synergistically and enhance the possibility for permanent installation. This probiotic capsule was tested against a placebo tablet from the manufacturer that contained only micro crystalline cellulose but was of identical taste, texture, and appearance. The dose was two tablets taken orally every day throughout the test period. 


\section{Subjects}

40 students suffering with chronic gingivitis were recruited from amongst National Dental College and Hospital, Derabassi.The mean age was 21 years with uneven sex distribution $(30 \mathrm{~F}, 10 \mathrm{M})$.

Subjects were outwardly healthy and further confirmed to meet the following criteria:

- Not currently visiting their dentist.

- Not taken antibiotic within last month.

- Not using probiotic supplements

All subjects provided written informed consent, and the study was approved by Reseach Ethics Committee constituted by National Dental College and Hospital, Derabassi.

\section{Study Design}

The study was performed as a double blind placebo controlled randomized trial over a 4-weeks test period. Subjects selected were divided in two groups, with 20 subjects in each group.

\section{Group A: Control group}

Group B: Probioticgroup

Subjects in the Control group consumed twoplacebo capsules every day. Those in the Probiotic group consumed two capsules containing probiotic (BifilacHp) every day. Subjects in each group were directed to place capsules in mouth and swallow it with water.They were also instructed not to change their oral hygiene regimens throughout the test period. Neither professional prophylaxis nor toothbrushing instructions were performed during or before the study period. The study consisted of two 2 weeks periods, a two weeks intervention period (T1-T2) and a two weeksposttreatment period (T2-T3). Clinical parameters and bacterial counts of salivary Streptococcus mutans, were evaluated at the baseline (T1), at the completion (T2) of medication and 2 weeks after medication (T3) (Fig-1). Four subjects were lost due to consumption of antibiotics during the follow -up period. Finally, 36 subjects, 17 in the Control and 19 in the Probiotic group were analysed.

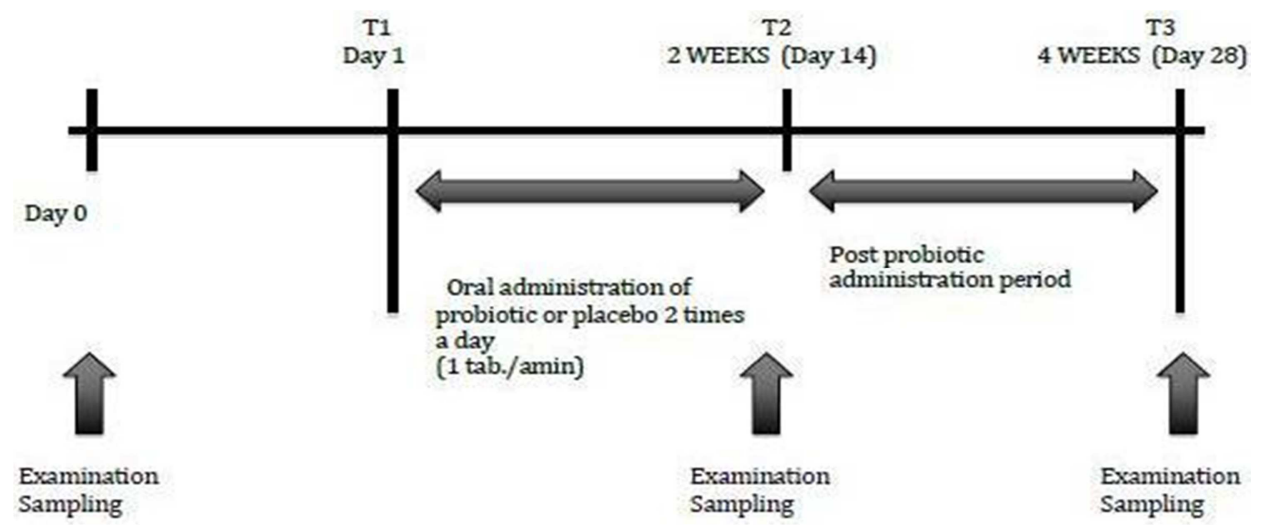

Fig. 1: Experimental Schedule

\section{Clinical Measurements}

The gingival condition was assessed by gingival index (GI; Loe and Sillness 1963). ${ }^{19}$ Supragingival plaque was scored by plaque index (PI; Sillness and Loe 1964). Both the indices were obtained from
Ramford's six teeth $(16,21,24,36,41$, and 44 in the FDI two-digit notation system) and considered representative of the whole dentition. ${ }^{27,29}$ When one of the selected teeth was missing in the oral cavity, parameters were obtained from the adjacent tooth in the same area of the jaw. 


\section{Saliva Sampling}

After the clinical measurements, saliva samples were obtained. The subjects were asked not to eat anything for one hour before collection of sample. The subjects were asked to chew sterile cotton swabs to stimulate saliva production. $2-3 \mathrm{ml}$ of saliva was collected in sterile disposable container.

\section{Laboratory Procedure}

Within half an hour of collection of samples, culture was done. Using $4 \mathrm{~mm}$ diameter inoculation loop, 10 ul of sample was streaked on Mitis Salivarius Bacitracin (MSB) Agar containing 1\% potassium tellurite and $10 \%$ sucrose. $^{7}$ This medium contains selective agents - crystal violet, potassium tellurite and bacitracin. These agents inhibit most gram negative bacilli and most gram positive bacteria except Streptococci. Sucrose is incorporated in $10 \%$ concentration which is utilised as energy source by Streptococci.

MSB plates were incubated in $5 \% \mathrm{CO}_{2}$ candle jar for 24 hours at $37^{\circ} \mathrm{C}$. Following incubation, colonies of Streptococcus mutans were identified by gram stain, culture morphology and Biochemical test.

On gram stain Streptococcus mutans appear as gram positive cocci arranged in short chains.

Biochemical tests: Streptococcus mutans is Catalase negative, Mannitol and Sorbitol fermentation positive

On culture - Streptococcus mutans forms raised, convex, undulate, opaque, pale blue colonies, granular frosted glass appearance sometimes exhibiting glistening bubble on surface of colony due to excessive synthesis of glucan from sucrose (Fig 2).

Colony count was done with a magnifying glass and count of Streptococcus mutans was expressed as number of colony forming units per $\mathrm{ml}$ of saliva (CFU / $\mathrm{mL}$ )

Semiquantitation of number of colonies was done by multiplying the actual colony with $1 \times 10^{2}$

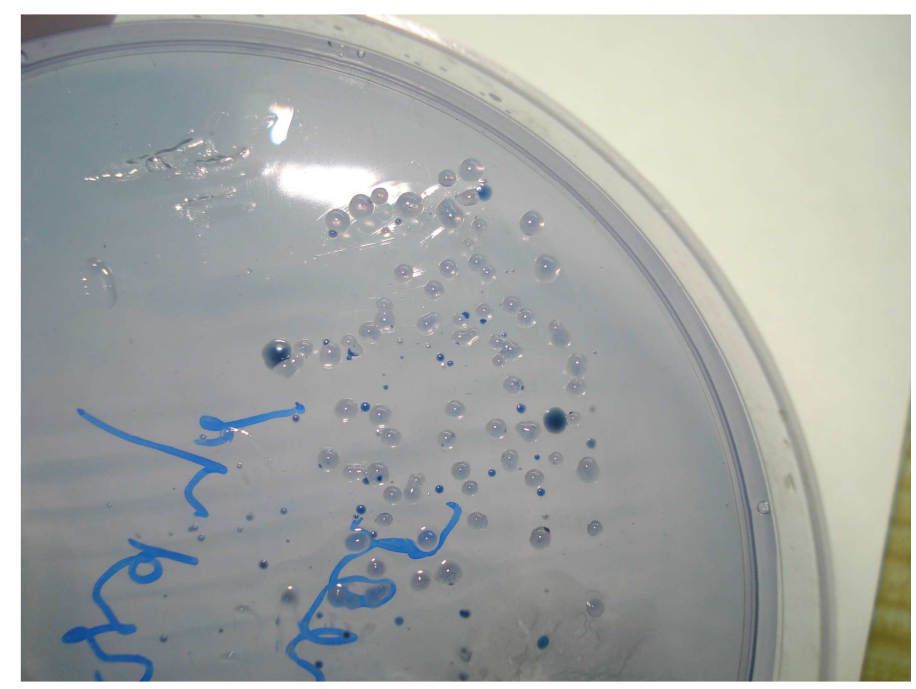

Fig. 2: Closer View of MSB Agar: Showing Convex, Pale Blue Colonies, Granular Frosted Glass Appearance of Streptococcus Mutans Colonies

\section{Results}

All subjects tolerated the surgical procedures well, experienced no post- operative complications, although three subjects in the control group and one subject in the test group were withdrawn during the follow-up period. These subjects 
took antibiotics during the study protocol and stopped the intake of tablets.

Clinical parameters and bacterial counts of salivary Streptococcus mutans, were evaluated at the baseline (T1), at the completion (T2) of medication and 2 weeks after medication (T3). The observations recorded were subjected to statistical analysis. No difference in results was found between male and female subjects.

The mean values of plaque index (PI) [Table-1], gingival index (GI) [Table-2], Streptococcus mutans levels [Table-3] at three points in time were evaluated. The efficacy of the two treatment modalities at T2 and T3 post-operatively were evaluated during the paired Student's t-test because the observations at the two points in time were expected to be closely related to each other. The two groups, Group A (Control group) and Group B (Probiotic group) were then comparatively evaluated over the three time intervals using the independent Student's t-test.

On analyzing the change in PI, and GIof the two groups, it was seen that there had been significant reduction in PIand GI in both the groups at all the three points of time.

The Streptococcus mutans level for both the groups was statistically significant at all the three points of time.

On comparative evaluation between the two groups, results indicated that Group-B (Probiotic group) exhibited statistically significant reduction in PI [Table-4] and Streptococcus mutans level [Table-5] than Group-A (Control group) over the entire span of the study.

Group-B (Probiotic group) provided statistically highly significant reduction in GI [Table-6] at T2 and T3, than Group-A.

Table1: Plaque Index of Group-A (Control Group) and Group-B (Probiotic Group) (in mm)

\begin{tabular}{|c|c|c|c|c|c|c|}
\hline \multicolumn{4}{|l|}{ Group-A } & \multicolumn{3}{|l|}{ Group-B } \\
\hline & T1 & T2 & T3 & T1 & T2 & T3 \\
\hline Mean \pm S.Em & $0.53 \pm 0.04$ & $0.41 \pm 0.03$ & $0.43 \pm 0.04$ & $0.51 \pm 0.03$ & $0.05 \pm 0.03$ & $0.52 \pm 0.032$ \\
\hline
\end{tabular}

S.Em: Standarderror of mean

Table2: Gingival Index of Group-A (Control Group) and Group-B (Probiotic Group) (in mm)

\begin{tabular}{l}
\begin{tabular}{|c|c|c|c|c|c|c|}
\hline \multicolumn{2}{|l|}{ Group-A } & \multicolumn{1}{l|}{ Group-B } \\
\hline & T1 & T2 & T3 & T1 & T2 & T3 \\
\hline Mean \pm S.Em & $0.49 \pm 0.03$ & $0.38 \pm 0.024$ & $0.39 \pm 0.27$ & $0.53 \pm 0.30$ & $0.54 \pm 0.03$ & $0.54 \pm 0.031$ \\
\hline
\end{tabular} \\
S.E \\
\hline
\end{tabular}

Table3: Streptococcus Mutans Count of Group-A (Control Group) and Group-B (Probiotic Group) (in CFU/mL)

\begin{tabular}{|c|c|c|c|c|c|c|}
\hline Group-A & T1 & T2 & T3 & T1 & T2 & T3 \\
& & & & & & \\
\hline Mean \pm S.Em & $24.14 \pm 23.13$ & $19.7 \pm 17.5$ & $20.04 \pm 17.55$ & $22.6 \pm 16.85$ & $23.4 \pm 16.55$ & $20.08 \pm 16.75$ \\
\hline
\end{tabular}

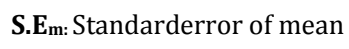


Table4: Comparison of mean Plaque Index scores between Group-A (Control Group) and Group-B (Probiotic Group)

\begin{tabular}{|l|l|l|l|}
\hline & T1 - T2 & T1 - T3 & T2 - T3 \\
\hline Group A mean & $0.12 \pm 0.016$ & $0.10 \pm 0.016$ & $-0.016 \pm 0.0069$ \\
\hline Group B mean & $-0.0058 \pm 0.0070$ & $-0.014 \pm 0.0053$ & $-0.0084 \pm 0.0052$ \\
\hline P - value & $0.00^{* *}$ & $0.00^{* *}$ & $0.35^{*}$ \\
\hline
\end{tabular}

P: Level of significance.

** Values are statistically highly significant at both $5 \%$ and $1 \%$ probability level.

* Values are statistically significant at both $5 \%$ probability level.

Table5: Comparison of Mean Gingival Index Scores between Group-A (Control Group) and Group-B (Probiotic Group)

\begin{tabular}{|l|l|l|l|}
\hline & T1 - T2 & T1 - T3 & T2 - T3 \\
\hline Group A mean & $0.105 \pm 0.013$ & $0.09 \pm 0.012$ & $0.0065 \pm 0.0047$ \\
\hline Group B mean & $-0.0074 \pm 0.0082$ & $-0.0137 \pm 0.0090$ & $-0.0063 \pm 0.0042$ \\
\hline P - value & $0.00^{* *}$ & $0.00^{* *}$ & $0.98^{\mathrm{NS}}$ \\
\hline
\end{tabular}

P: Level of significance.

** Values are statistically highly significant at both $5 \%$ and $1 \%$ probability level.

NS: Values are statistically non-significant at both $5 \%$ and $1 \%$ probability level.

Table6: Comparison of Mean Streptococcal Mutans Counts between Group-A (Control Group) and Group-B (Probiotic Group)

\begin{tabular}{|l|l|l|c|}
\hline & T1 - T2 & T1 - T3 & T2 - T3 \\
\hline Group A mean & $24.40 \pm 23.61$ & $24.09 \pm 23.63$ & $-0.34 \pm 0.29$ \\
\hline Group B mean & $-14.86 \pm 13.10$ & $18.51 \pm 18.97$ & $33.37 \pm 23.36$ \\
\hline P - value & $0.28^{*}$ & $0.29^{*}$ & $0.18^{*}$ \\
\hline
\end{tabular}

P: Level of significance.

- Values are statistically significant at both $5 \%$ probability level.

\section{Discussion}

The paradigm that oral inflammation is the root cause of not only periodontal disease and caries, but cardiovascular disease, diabetes, arthritis and many more is rapidly emerging.

Treating the oral infection by reducing the number of pathogenic oral microorganism and establishing a favourable oral envoirnment to promote predominantly remineralization of tooth structure over time will stop the disease process. ${ }^{8}$
Probiotic technology represents a breakthrough approach to maintain oral health by utilizing natural beneficial bacteria commonly found in healthy mouths to provide natural defense against those bacteria thought to be harmful to teeth and gums.

Probiotic may affect the oral ecology by specifically preventing the adherence of other bacteria and by modifying the protein composition of salivary pellicle. Probiotic bacteria could modify the protein composition of the pellicle by two different methods, namely binding to and the degradation of salivary proteins. ${ }^{\mathbf{1 7}}$ 
Probiotic lower the ph so that microorganism cannot form dental plaque and calculus that causes oral inflammation. Polonskaya first described the phenomena that probiotic such as Lactobacilli acidophilus strains may inhibit the invitro growth of other bacteria. ${ }^{9}$

Lactobacilli can produce low moleculer weight bacteriocins with an inhibitory effect against a wide range of bacterial species including oral Streptococci, causative agent of caries and gingivitis. ${ }^{28,30}$

Fusiform nucleatum has been regarded as a chain microorganism in dental plaque formation, possessing the ability to coaggregate with the majority of other bacteria in the oral cavity. Lactobacilli coaggregate with F. nucleatum at nearly $90 \%$, thus modulating composition of oral biofilms. ${ }^{11}$

Lactobacilli had been shown to be the strongest inhibitor of AActinimycetemcomitans, $\mathrm{P}$ gingivalis and $\mathrm{P}$ intermedia, potent microorganisms responsible for periodontal destruction. ${ }^{20}$

Probiotic microorganisms do not act exclusively by affecting the microbiota, but also protect the oral cavity through the promotion of a beneficial host response. They exert effects either by modulating immunological parameters, epithelial permeability and bacterial translocation, or by providing bioactive or regulatory metabolites. ${ }^{5}$ The latter effects are appealing for periodontal healthcare because current evidence shows that the destruction of the periodontium is substantially mediated by the host and driven by the bacterial challenge. ${ }^{23}$ Therefore, probiotics might not only suppress the emergence of endogenous pathogens or prevent the superinfection with exogenous pathogens but they might also protect the oral cavity through the promotion of a beneficial host response. ${ }^{21}$

Probiotic bacteria or their products (e.g. metabolites, cell wall components and DNA) can be recognized by host cells such as epithelial cells and immune cells. ${ }^{\mathbf{1 6}}$. It is known that probiotics can regulate the expression of phagocytosis receptors in the neutrophils of healthy individuals and enhance natural killer cell activity. ${ }^{18,31}$

In the present study, beneficial impact of probiotic bacteria is well established by statistical significant reduction in plaque index (PI) and level of Streptococcus mutans in Group-B (Probiotic group) as compared to Group-A (Control group). ${ }^{2,3}$ The observed improvement in clinical status may be attributed to the reduced levels of cariogenic as well as periodontal pathogens and effective colonization of the probioti bacteria within the oral cavity. Significant reduction is also observed in gingival index (GI) in Group-B (Probiotic group) as compared to Group-A (Control group) at T2 and T3. Non significant change between T2-T3 signify that improvement in gingival condition tend to remain stable after cessation of probiotic intake. Residence time of probiotics in oral cavity after treatment withdrawal is yet not known. The results did not suggest that a permanent installation can take place in person with established microflora. ${ }^{13,14}$ But, their mechanism of action suggested that they need not to permanent colonize their host; even repeated daily use of probiotic over a long period of time will support its increased levels in the oral cavity. Since it seems unlikely that probiotics have any significant residual effect after discontinuation of intake, daily intake seems to be a prerequisite for potential action. ${ }^{\mathbf{1 4 , 1 5}}$

\section{Conclusion}

Probiotics used for the management of oral disease may reduce the cost of conventional therapy and prevention programs. The idea of replacing harmful microorganisms with non-harmful, inactivated or genetically modified bacteria is attractive. With the focus on disease prevention and optimal health for all ages, the potential for probiotics use is enormous. In this study improvement in gingival health and decrease in Streptococcal mutans levels in Probiotic group warrant its further exploration in prevention of gingival diseases and caries. Efforts should be made to increase the awareness of the general 
dental practitioner with this aspect of oral disease therapy and encourage the implementation of the concept of "food rather than medicine". Much more scientific developments are needed to have a better understanding of these tiny forms of lives in order to broaden their potential applications.

\section{References}

1. Bowden, G. H. W. (1991). 'Which Bacteria are Cariogenic in Man in Markers of High and Low Risk Groups and Individuals for Dental Caries,' In: Johnson NW, Editor. Cambridge University Press, p.266-86.

2. Caglar, E., Kavaloglu Cildir, S., Ergeneli, S., Sandalli, N. \& Twetman, S. (2006). "Salivary Mutans Streptococci and Lactobacilli Levels after Ingestion of the Probiotic Bacterium Lactobacillus Reuteri ATCC 55730 by Straws and Tablets," Acta Odontologica Scandinavica, 64 314-318.

3. Caglar, E., Kavaloglu, S. C., Kuscu, O. O., Sandalli, N., Holgersson, P. L. \& Twetman, S. (2007). "Effect of Chewing Gums Containing Xylitol and Probiotic Bacteria on Salivary Mutans Streptococci and Lactobacilli," Clinical Oral Investigations, Epub ahead of print, doi: 10.1007/s00784-007-0129-9.

4. Cornelli, E. M., Guggenheim, B., Stingele, F. \& Neeser, J.- R. (2002). "Selection of Dairy Bacterial Strains as Probiotics for Oral Health," European Journal of Oral Sciences, 110 218-224.

5. de Vrese, M. \& Schrezenmeir, J. (2008). "Probiotics, Prebiotics and Synbiotics," Food Biotechnology, 1111-66.

6. Food and Agriculture organization and World Health Organisation Expert Consultation (2001). 'Evaluation of Health and Nutritional Properties of Powder Milk and Live Lactic Acid Bacteria,' [online], Available at http//www.who.int/foodsafety/fsmana gement/en/probioticguideline.Pdf.
7. Gold, O. G., Jordan, H. V. \& Van Houte, J. (1973). "A Selective Medium for Streptococcus Mutans," Archives of Oral Biology, 18 1357-64.

8. Haukioja, A., Loimaranta, V. \& Tenovuo, J. (2008). "Probiotic Bacteria Affect the Composition of Salivary Pellicle and Streptococcal Adhesion in Vitro," Oral Microbiology and Immunology, 23 336343.

9. Ishihara, K., Miyakawa, H., Hasegawa, A., Takazoe, I. \& Kawai, Y. (1985). "Growth Inhibition of Streptococcus Mutans by Cellular Extracts of Human Intestinal Lactic Acid Bacteria," Infection and Immunity, 49692-694.

10.Kligler, B. \& Cohrssen, A. (2008). "Probiotics," American Family Physician, 78 1073-1078.

11.Koll-Klais, P., Mandar, R., Leibur, E., Marcotte, H., Hammarström, L. \& Mikelsaar, M. (2005). "Oral Lactobacilli in Chronic Periodontitis and Periodontal Health: Species Composition and Antimicrobial Activity," Oral Microbiology and Immunology, 20 354361

12.Loesche, W. J., Rowan, J., Straffon, L. H. \& Loos, P. J. (1975). "Association of Streptococcus Mutans with Human Dental Decay," Infection and Immunity, 111252-60.

13. Meurman, J. H. (2005). "Probiotics: Do They Have a Role in Oral Medicine and Dentistry?," European Journal of Oral Sciences, 113 188-196.

14. Meurman, J. H., Antila, H. \& Salminen, S. (1994). "Recovery of Lactobacillus Strain GG (ATCC 53103) from Saliva of Healthy Volunteers after Consumption of Yoghurt Prepared with the Bacterium," Microbial Ecology in Health and Disease 7 295-98.

15. Nikawa, H., Makihira, S., Fukushima, H., Nishimura, H., Ozaki, Y., Ishida, K. et al. (2004). "Lactobacillus Reuteri in Bovine Milk Fermented Decreases the Oral 
Carriage of Mutans Streptococci," International Journal of Food Microbiology 95 219-223.

16.0elschlaeger, T. A. (2010). "Mechanisms of Probiotic Actions - A Review," International Journal of Medical Microbiology, 300 57-62.

17.Polonskaya, M. S. (1952). 'Antibiotic from Acidophilus,' Microbiologiya, 1952; 21:303-310.

18.Pelto, L., Isolauri, E., Lilius, E. M., Nuutila, J. \& Salminen, S. (1998). "Probiotic Bacteria Down Regulate the Milk Hypersensitive Subjects but Have an Immunostimulatory Effect in Healthy Subjects," Clinical and Experimental Allergy Journal of the British Society of Allergy and Clinical Immunology.

19. Ramford, S. P. (1959). "Indices for Prevalence and Incidence of Periodontal Disease," Journal of Periodontology, 30 51-59.

20.Riccia, D. N. D., Bizzini, F., Perilli, M. G., Polimeni, A., Trinchieri, V., Amicosante, \& Cifone, M. G. (2007). 'AntiInflammatory Effects of L.brevis (DC2) on Periodontal Disease,' Oral Dis, 13376385.

21.Roberts, F. A. \& Darveau, R. P. (2002). "Beneficial Bacteria of the Periodontium," Periodontology 2000, 30 40-50

22.Rupesh, S., Winnier, J. J., Nayak, U. A., Rao, A. P. \& Reddy, N. V. (2010). "Comparative Evaluation of the Effects of an Alum Containing Mouthrinse and a Saturated Saline Rinse on the Salivary Levels of Streptococcus Mutans," Journal of Indian Society of Pedodontics and Preventive Dentistry, 28 (3) 138-144.

23.Sanz, M. \& Quirynen, M. (2005). "Advances in the Aetiology of Periodontitis," Journal of Clinical Periodontology, 32 (suppl 6): 54-56.

24.Selvan, A. K., Singh, R. C. \& Prabhu, T. (2011). 'Antibacterial Activity of Bee
Propolis against Clinical Strains of Streptococcus Mutans and Synergism with Chlorhexidine,' International Journal of Pharmaceutical Studies and Research, II(I) 85-90.

25.Senok, A. C., Ismaeel, A. Y., Botta, G. A. (2005). "Probiotics: Facts and Myths," Clinical Microbiology and Infection, 11 958-66.

26.Shimauchi, H., Mayanagi, G., Nakaya, S., Minamibuchi, M., Ito, Y., Yamaki, K. \& Hirata, H. (2008). "Improvement of Periodontal Condition by Probiotics with Lactobacillus SalivariusWB21: A Randomized Doubleblind, PlaceboControlled Study," Journal of Clinical Periodontology, 35 897-905.

27.Silness, J. \& Loe, H. (1964). "Periodontal Disease in Pregnancy. II. Correlation between Oral Hygiene and Periodontal Condition," Acta Odontologica Scandinavica, 24 747-759.

28.Silva, M., Jacobus, N. V., Deneke, C. \& Gorbach, S. L. (1987). "Antimicrobial Substance from a Human Lactobacillus Strain," Antimicrobal Agents and Chemotherapy, 31 1231-1233.

29.Soben Peter (2006). 'Essentials of Preventive and Community Dentistry,' 3rd edition, P-144-145.

30.Stamatova, I., Kari, K. \& Meurman, J. H. (2008). 'In Vitro Evaluation of Antimicrobial Activity of Putative Probiotic Lactobacilli against Oral Pathogens,' International Journal of Probiotics and Prebiotics, 2 225-232.

31.Takeda, K., Suzuki, T., Shimada, S. I., Shida, K., Nanno, M. \& Okumura, K. (2006). 'Interleukin-1 is Involved in the Enhancement of Human Natural Killer Cell Activity by Lactobacillus Casei Shirota,' Clinical and Envoirnment IImmunogy, 146 109-115 